\title{
Cinematic Bodies
}

\author{
Jenny Chamarette
}

School of Languages, Linguistics and Film, Queen Mary University of London, Mile End Road, London E1 4NS, UK; j.chamarette@qmul.ac.uk; Tel.: +44-20-7882-5632

Academic Editor: Annetta Alexandridis

Received: 13 May 2016; Accepted: 16 May 2016; Published: 21 June 2016

It is difficult to imagine a cinema without bodies. When Steven Shaviro published The Cinematic Body (Minneapolis: University of Minnesota Press, 1993), he begged for a return to a materialist aesthetics of cinema, which placed the intensities of the body first and foremost on the contemporary screen. This was a plaintive, angry cry for a return to the body in film theory, away from prevailing psychoanalytic readings of the significatory structures operating in the cinema. One might say that the work of Vivian Sobchack had already answered this call to put the body first. Her formative volume, The Address of the Eye: A Phenomenology of Film Experience (Princeton NJ: Princeton University Press, 1991), sketched out what a phenomenological account of film experience might be, in the light of 20th century alternatives to psychoanalysis and poststructuralist philosophy.

There has since been an explosion of scholarships in the 21st century on the materiality of the cinematic body, on embodied phenomenologies of the moving image, on modes of materialist film aesthetics, and on the provocations of affect, emotion, and enervation in and about film. However, the body has always been important to cinema. In early cinema, human, animal, and machine bodies were composite entities, from the Lumière brothers' Eurocentric visions of the living planet, to Dziga Vertov's Kinoeye. The physical expressiveness of silent stars Keaton and Chaplin, Brooks and Gish was a distinctive hallmark of their performances, just as gestures and body language, both on and off-screen, defined the stars of the Golden Age of Hollywood that followed them.

The cultures of national and transnational cinemas have encoded a diversity of bodily gestures, traversing the arts of performance and representation. Also, as studies of the moving image have expanded to incorporate video art, structuralist film and animation, so too has an expanded sense of the body emerged, particularly relating to synaesthesia, haptics and sensation. The body of the film medium: celluloid, magnetic video, DVD, digital file, internet stream, has equally informed the work of generations of avant-garde film and artist's moving image.

This guest-edited Special Issue aims to provide a cutting-edge perspective on contemporary scholarship examining bodies through cinema and the moving image. We invite scholarly articles on the theme, and would especially welcome perspectives on non-anglophone, transcultural and/or global moving images. Practice-based research discussions are also welcome.

Potential topics include:

- Physicality: athletic/sporting bodies, bodily impairment, injured/ill bodies, dying bodies, bodily acts and performing bodies

- Bodily deviance and normativity: deviant, exiled and abject bodies, non-normative bodies, bodily emissions

- Identity and embodied experience: bodies and ethnicity, gendered and transgendered bodies, queer bodies, sexualised and sexualising bodies

- Non-human and post-human bodies: non-human animal bodies, posthuman bodies, bodies and/as environments, being without a body

- Bodies, myths and technology: cyborgs, prostheses, bodies and machines, mechanical bodies, celestial/heavenly/planetary bodies, illusory bodies 
- Film as a body: Intermediality and materiality, theories of cinematic embodiment, embodied spectatorship, cinematic sensation and affect

- The body politic: bodies and community, collectivity, assemblages, bodily activism

Conflicts of Interest: The author declares no conflict of interests. article distributed under the terms and conditions of the Creative Commons Attribution (CC-BY) license (http://creativecommons.org/licenses/by/4.0/). 